\title{
Resolving the Systemic Bias against Students from Disadvantaged Classes in Higher Education in India: The Case of Indian Institutes of Technology
}

\author{
Digvijay S. Sujlana
}

\begin{abstract}
Purpose of this paper is to present an idea that may be retrofitted into present day education policies in India, in order to mitigate the effect of the bias against students from disadvantaged classes. Taking the case of higher education in general and the Indian Institutes of Technology in particular, the paper first presents the effects of globalization on policies followed by the government's short sightedness in policymaking (like infusing reservations without required amendments) leading to the persistence of the bias that makes gaining admission and performing during the course of studies difficult for students from disadvantaged classes. The paper rounds up policies surrounding the issue and their inefficacies, and concludes with a retrofit that could be employed in the short term, whilst stating why it will help in negating the effects of the bias.
\end{abstract}

Index Terms-Systemic bias, higher education in India, students from disadvantaged classes, Indian Institutes of Technology.

\section{INTRODUCTION}

Inequity in access to education across levels has been a persistent social problem in India. Purpose of this paper is to present an idea that may be retrofitted into present day education policies in India, in order to mitigate the effect of a bias against students from disadvantaged classes. Taking the case of higher education in general and the Indian Institutes of Technology in particular, the paper first presents the effects of globalization on policies followed by the government's short sightedness in policymaking leading to the persistence of the bias that makes gaining admission and performing during the course of studies difficult for students from disadvantaged classes. The paper rounds up policies surrounding the issue and their inefficacies, and concludes with a retrofit that could be employed in the short term, whilst stating why it will help in negating the effects of the bias.

\section{EFFeCt OF GLOBALIZATION ON Higher EdUCATION POLICIES}

Over the past two and a half decades the neo-liberal instinct in policy making has been bestowed upon as a "gift" of globalization on education, similar to every other sector. In

Manuscript received September 25, 2015; revised December 2, 2015 This work was conducted under the aegis of the social policy faculty at the Lee Kuan Yew School of Public Policy, National University of Singapore.

D. S. Sujlana is with the Lee Kuan Yew School of Public Policy, National University of Singapore, Singapore (e-mail: digvijay.sujlana@u.nus.edu).
India the reasons behind the urgency of imparting education is no longer the need for building up national capability via government intervention, but is structured as a response to the requirements of skills relevant to the Indian industry, which has seen tremendous growth across economic activities with the influx of global processes and standards. The National Policy on Education of the 1970s and 1980s aimed at universalizing education for achieving national integration along side economic development. Even though this has persisted, the assurance of up to secondary education under the Right to Education Act of 2009 is an indication of the same, the major concerns of the present day government are first, to sustain higher enrolment in tertiary education and second, to ensure a market ready resource of human capital akin to the requirements of the industry. Having said that, in terms of student number, India already has the world's second largest higher education. 2014 saw India's enrolment in tertiary education surpass that of the United States' [1]. It is therefore the second issue that should be higher on the government's agenda. The article "India's education system needs to be more job oriented," in [2] in one of India's leading national daily's bears evidence of the same.

Taking heed of this the government has decided upon a large-scale development of public universities to address the skill deficit across the wide spectrum of available jobs. If successful this will ensure a further increase in tertiary education enrolment. Whilst the basic tenets of present day education policies (i.e. universalization, ensuring socio-cultural and socio-economic integration) on which admission will be awarded, remain the same. They bear no signature of ensuring that the long-standing issue of inequity in terms of gaining access, i.e. admission. Even after inculcating the marquee affirmative action (AA) policy of ensuring equal opportunity of access via reservation for the students from socially disadvantaged classes (SSDCs) $)^{1,2}$, additional policies addressing a systemic bias that bars this policy to have a substantial positive impact on minority classes are missing. To elaborate further on the systemic bias this paper takes the case of the Indian Institutes of Technology

${ }^{1}$ Socially Disadvantaged classes/groups in India - Considered as those belonging to the Scheduled Castes (SCs), Scheduled Tribes (STs), Other Backward Classes (OBCs), Girls, Children with special needs and minorities. These groups are the benefactors of the reservation policy in India. (Source: Socially disadvantaged groups, $10^{\text {th }}$ Five Year Plan Document, Planning Commission $\quad$ [Online]. $\quad$ Ch. 4.1. Available: http://planningcommission.nic.in/plans/planrel/fiveyr/10th/volume2/v2_ch 4_1.pdf)

2 This paper takes into consideration students belonging to Schedule Castes (SCs), Scheduled Tribes (STs) and Other backward classes to form part of the SSDCs. 
(IITs), globally renowned as centers of academic excellence imparting higher technical education.

\section{THE SYSTEMIC BIAS}

The Institutes of Technology Act of 1961 renders the IITs as institutions of national importance [3]. Even though the IITs have continuously churned out global leaders they have been plagued with the problem of inequitable treatment of SSDCs. Studies conducted by [4] and [5] elaborate on the ineffectiveness of these institutes in ensuring equivalent professional development of students gaining access through reservations when compared to the non-reserved category students. Reports such as ' $90 \%$ of students expelled from IIT Roorkee belong to reserved categories' [6] provide further evidence on how the IITs have not been able to address this discrepancy. In light of the inefficiencies caused by the affirmative action policy of reservation, a deeper look into the efficacy of the present government's decision to increase the number IITs, with each state having an institute of its own, is warranted. This will result in an increase in the total number of IITs, which grew to 19 in 2015 from seven in 2001, to 30 in the coming years without putting in place processes to negate the above mentioned systemic bias.

\section{PERSISTENCE OF THE BIAS}

Gaining admission to the IITs is highly competitive, and is achieved by clearing a multi-level entrance examination, the Joint Entrance Examination (JEE). In 2013, 1.4 million [7] students registered for the JEE to compete for $9,885^{3}$ seats at the 17 IITs. This equals to an acceptance rate of less the one percent. For a student to have a realistic shot at securing admission, apart from sound basics, the student often requires going beyond the scope of books prescribed by the schooling boards. SSDCs often come from government schools in semi-urban or rural areas where delivery is known to lack quality leading to a poor grounding in basics. There has also been a long-standing issue in the variability of the curriculum across states. The institutional setup in India, where the final authority are state governments, has made it very difficult for schools across states to follow the mantra of teaching the same thing, in the same manner and in the same time of the students' schooling timespan, thus leading to inequitable personal and professional gains.

Also amongst these a large percentage come from households lingering in poverty of which a large proportion suffer from extreme poverty ${ }^{4}$, which takes us to the second aspect of the bias. Of the students getting admitted to the IITs around $50 \%$ to $60 \%$ [8] take up specialized coaching apart

\footnotetext{
3 "9.885 seats available in 17 IITs; results on June 23," The Hindu, June 21, 2013 [Online]. Accessed at http://www.thehindu.com/news/cities/Hyderabad/9885-seats-available-in-1 7-iits-results-on-june-23/article4834329.ece

${ }^{4}$ In rural areas the poverty ratio in Scheduled Tribes is $45 \%$, in Schedule Castes is $31.5 \%$ and in Other Backward Classes in $22.6 \%$ as compared to this the ratio is just $15 \%$ for non-reserved categories as registered in 2011-12. (Source: Poverty Estimates for Social Groups: 2004-05 and 2011-12, Planning Commission, Government of India. Accessed at http://planningcommission.gov.in/reports/genrep/rep_pov1303.pdf)
}

from attending the regular school curriculum, despite the JEE focusing heavily on standard $11^{\text {th }}$ and $12^{\text {th }}$ curriculum. Institutes imparting such coaching are mostly private and start attracting students as early as standard $8^{\text {th }}$ and charge a tuition fee of around INR 200,000 to 270,000 in metros and around INR 80,000 in non-metros per year [9]. India's per capita income remains INR 74,290 [10] and makes external private coaching inaccessible to students from low-income households, who earn less than INR 200,000 [11] a year. The coaching industry thrives on the faith shown in it by the parents and the students alike owing to the dysfunctional and inadequate school system. A conjunction of poor schooling and lack of access to coaching therefore makes it very difficult for SSDCs to compete against their well off counterparts. The government thus finds reservation as an 'optimal' system, without having achieved any significant improvement in the quality of delivery at the aforementioned schools, for SSDCs to gain admission to institutes like the IITs.

While reservation facilitates access, it pits students with low academic ability, majorly the SSDCs, with students of a higher academic ability. In JEE 2013 the qualifying marks for students belonging to Scheduled Tribes / Scheduled Castes was $50 \%$ [12] of what the students from non-reserved categories obtained. [13] showed how this situation lead to the further reduction in human capital of students from reserved categories (aka SSDCs), implying that the few disadvantaged students who make it to the IITs each year struggle to make most of their education. Ref [5] explains how SSDCs find it tough to catch-up during the course of their studies and that there still remained a marked mismatch between the requirements of recruiters and the abilities of the SSDCs.

Put together, the dysfunctional school system that the SSDCs have access to along with low-income levels has created an ecosystem with an inbuilt bias that makes it difficult for the SSDCs to make best use of the opportunity created via affirmative actions of the government. This has been further accentuated due to the failure of other long-standing government policies/initiatives surrounding education. The following section sheds light on the inefficacy of some of these policies aimed at increasing access to quality schools and effective targeting under reservation.

\section{OTHER INEFFECTIVE POLICIES}

None of the policies aimed at rectifying the dysfunctional government school system, be it the Right to Education Act (2009) or the Mid-day Meal Scheme, ensure that a mechanism of additional support to prepare students for entry into higher education is put in place in schools. These solely aim at increasing enrolment and are not commensurate with quality. ASER reported that $41.7 \%$ [14] of the fifth standard students in government schools could not read books prescribed in the second standard, other metrics such as dropouts, pass percentages are discouraging as well. The RTE's effort to ensure quality for SSDCs by integrating them with other students via the $25 \%$ reservation in private schools is irrelevant in semi-urban and rural areas where majority of the 
schools are government aided.

The Jawahar Navodaya Vidyalayas (JNVs) is a system of government run residential schools to serve the objectives of excellence coupled with equity and social justice [15]. With $75 \%$ reservation for students from rural areas in addition to the standard reservation with full fee waiver for SSDCs, has been successful in terms of ensuring highest pass percentages and marginal dropout rates when compared with other government school systems. In inception since the 1980s, this school system suffers from lack of scale. In a study conducted by the government in 2015 showed that about $60 \%$ [15] of the Principals felt that at less than 600 schools pan India there is not enough supply to cater to the rural needs. The study also highlights that the states are not doing enough to educate the masses about the JNVs, almost $60 \%$ of the JNVs are not ideally located and that $37 \%$ of the schools lack computer facilities leading to schools not functioning at optimal levels. Additionally there is no mention of preparing students for the admission process to higher education institutes making way for the bias to flourish.

For effective targeting under reservations across education levels, the government had introduced the "creamy layer" criterion that barred households belonging to the Other Backward Classes but earning more than a threshold amount annually from enjoying reservation. Given the extent of the informal market in India, it has made the process of validation of household income ineffective therefore made it close to impossible to ensure that the intended beneficiaries enjoy the fruits of reservation.

Even though the underlying social objectives of the aforementioned policies are unquestionable, a common factor is the focus on the output (i.e. increasing enrolment) rather than the outcome (i.e. ensuring quality and effective targeting) Also all these policies are focused at the long term whereas interventions reaping benefits in the very short term are the need of the hour.

\section{THE SOLUTION}

A look into the "services" provided to the SSDCs at the JNVs and the IITs, shows a complete lack of access to both personal and professional support systems, such as mentors or advisors that can guide a student in standard $10^{\text {th }}$ through the entire course of his/her high school and higher education respectively. All that is said is that teachers should don this hat but no real effort in capacity building of this particular skill-set has been seen yet. There is therefore a need for a formalized mentorship program starting from school through the entire course of higher studies directed primarily at the SSDCs.

An individual continuously needs to take decisions at various stages in his/her lifetime as a student. Some of the most critical being the choice of subjects before entering the senior-secondary stage, the choice of joining university vis-à-vis a professional college or the overbearing choice of pursuing organizations whilst at college to start off ones career. [16] through an audit of university support services in Australia showed that personal support services were most needed by students from low socioeconomic backgrounds and were often unavailable when required, making it even difficult for such students to settle down at university. The Indira Gandhi National Open University (IGNOU), established to provide distance learning has seen high rates of dropouts due to lack of student support systems [17]. Lacking at the university level, arguments in the previous section show that student support systems are non-existent in government schools in semi-urban and rural areas.

The government of India's Rashtriya Avishkar Mission, under which government schools will be mentored by institutes such as the IITs through student exchanges, student visits etc. [18], comes closest to giving any heed to this gap. This initiative is structured at the institutional level and mainly to sensitize students to the importance of science and mathematics; where the requirement actually is that of active up-close and personal interventions. In higher education, [19] showed how mentored students' registered higher grade points and a lower dropout rate when compared with non-mentored students. [20] stressed on how peer-mentoring, involving vulnerable students, through the entire course of studies as an intervention ensured their success and retention. Giving further evidence on the efficacy of mentorship, the best of multi-national corporations assign career managers (aka mentors) to new recruits to guide them towards a successful career. [21] showed how mentorship infused self-confidence, assertiveness and autonomy in student midwives; SSDCs have to wade through similar vulnerabilities hence the need for a mentorship mechanism. This need has also been stressed upon by in the first year of medical studies, even though limited in scope [22]. Sections of the civil society have taken note of this requirement; not-for-profit organizations like Avanti Fellows provide mentorship to students from low-income households. Their learning centers have adopted the peer-learning pedagogy thereby creating a learning environment conducive for inter-personal and academic development. The effect is very evident, with 51 of their $89^{5}$ students having cleared the first stage of JEE 2015. Having said that the scale achieved by similar organizations remains limited.

\section{RETROFITTING FORMALISED MENTORSHIP}

Suggesting the possible structuring and commenting on the financial viability of a pan-India mentoring program at the government schools and universities is outside the scope of this paper. Running a small-scale pilot by the central government in order to provide evidence to the state governments on the effectiveness of mentorship is thus being suggested. A framework, keeping in mind the role of IITs, on how mentorship can be retrofitted as an added "service" as part of the reservation policy is therefore presented.

The mentorship pilot could include running two parallel programs. In the first (henceforth referred to as Program I) multiple teams consisting of instructors and students at an IIT may adopt JNVs across districts in the proximity. As and when IITs are opened in each state the program can be scaled.

\footnotetext{
${ }^{5}$ Avanti Fellows, http://avantifellows.org/
} 
This could be integrated into the National Service Scheme, an initiative under the aegis of the Ministry of Youth Affairs and Sports of the central government, under which students across IITs engage in national building activities. The Rashtriya Avishkar Abhiyaan (a Ministry of Human Resource Development initiative) can also make use of this setup; this would thus require joint ownership amongst the two ministries. Under the second program (henceforth referred to as Program II), a formal setup for providing mentorship to SSDCs already at IITs during the entire course of studies should be put in place. This could be achieved by partnering with organizations such as Avanti Fellows. If carried out as suggested, the two pilot programs can be run by using the resources in place.

Under pilot Program I, JNV SSDC students from standard $10^{\text {th }}$ onwards can be targeted with the motive of making them aware about the nuances surrounding the JEE. This setup would start generating evidence within a year. The effectiveness of one, two and three year mentorship programs provided to standard $12^{\text {th }}, 11^{\text {th }}$ and $10^{\text {th }}$ respectively can be evaluated by comparing their performance in the JEE. Under pilot Program II, the aim would be to guide the SSDCs through choice of electives and making them aware on the professional opportunities and corresponding requirements to enable them to work towards securing a job. Tracking grade point averages and the performance of the SSDCs in securing jobs may be tracked to test the effectiveness of this program.

The programs will also require training the mentors/advisors on the nuances of the mentor-mentee relationship; this will hold the key to the successful implementation of the pilots. The pilots focused at the SSDCS can help the government in arriving at a solution that would directly affect human capital development and indirectly achieve effective targeting under reservation. Consequently mitigating the bias barring equitable treatment.

\section{CONCLUSION}

By looking at the specific case of the IITs in India, the paper identifies how students from disadvantaged classes find it difficult to gain access and perform whilst at premier institutes in India. The dysfunctional government school system that majority disadvantaged students have access to and their low income backgrounds are identified as the root causes. The inequitable treatment of such students is accentuated by the ineffective policies surrounding education. The paper presents formalised mentorship as a retrofit that could be employed in the short term, whilst stating why it will help in negating the effects of the bias.

The main motive behind the paper is to put out an idea to solve a persisting problem, thus discussing the entire gamut of challenges in implementation is currently outside its scope. Having said that, a comparative study on how similar mentorship programs are being run in other countries is warranted and will be the focus in the follow up paper.

\section{ACKNOWLEDGMENT}

I would like to thank Professor M Ramesh at the Lee Kuan
Yew School of Public Policy for guiding and pushing me to analyse a critical social policy problem in India. Without his consistent feedback this paper would not have been possible.

\section{REFERENCES}

[1] P. G. Altbach, "India's higher education challenges," Asia Pacific Educ. Rev., vol. 15, pp. 503-510, June 2014.

[2] (September 7, 2015). India's education system needs to be more job oriented. Hindustan Times. [Online]. Available: http://www.hindustantimes.com/comment/india-s-education-system-n eeds-to-be-more-job-oriented/article1-1388102.aspx

[3] (1961). The Institutes of Technology Act. [Online]. Available: http://www1.iitb.ac.in/legal/IITsAct.pdf

[4] M. Bertrand, R. Hanna, and S. Mullainathan, "Affirmative action in education: Evidence from engineering college admissions in India," Journal of Public Economics, November 2009.

[5] V. Frisancho and K. Krishna, "Affirmative action in higher education in India: targeting, catch up, and mismatch," Springer Science+Business Media Dordrecht, July 2015.

[6] (July 13, 2015). 90\% of students expelled from IIT Roorkee belong to reserved categories. Economic Times. [Online]. Available: http://articles.economictimes.indiatimes.com/2015-07-13/news/6437 0876_1_preparatory-course-students-iit-roorkee

[7] (December 28, 2012). Record number of candidates for JEE 2013. The Times of India. [Online]. Available: http://timesofindia.indiatimes.com/home/education/news/Record-nu mber-of-candidates-for-JEE-2013/articleshow/17787459.cms

[8] (October 2, 2013). 50\% of IIT entrants not from coaching classes. The Times of India. [Online]. Available: http://timesofindia.indiatimes.com/home/education/news/50-of-IIT-e ntrants-not-from-coaching-classes/articleshow/23374734.cms

[9] (November 6, 2014). No slowdown for IIT coaching institutes despite new JEE pattern's stress on XII. Business Standard. [Online]. Available:

http://www.business-standard.com/article/economy-policy/no-slowdo wn-for-iit-coaching-institutes-despite-new-jee-pattern-s-stress-on-xii114110600021_1.html

[10] (February 7, 2014). India $\$ 1.7$ trillion economy, per capita income rises to Rs 74,290. The Economic Times. [Online]. Available: http://articles.economictimes.indiatimes.com/2014-02-07/news/4712 6380_1_2004-05-prices-lakh-crore-capita-income

[11] (November 15, 2012). Income criteria for EWS, LIG housing revised. The Hindu. [Online]. Available: http://www.thehindu.com/news/cities/Delhi/income-criteria-for-ews-1 ig-housing-revised/article4097423.ece

[12] P. Gupta and R. N. Gupta. (2013). Summary of JEE (Advanced) [Online]. Available: http://www.iitk.ac.in/new/data/jee-report/JEE-2013\%20Report.pdf

[13] A. Kochar, "Affirmative action through quotas: The effect on higher education in India," Stanford Center for International Development, Stanford University, June 2009.

[14] (September 17, 2015). RTE: Good intent but drive lacking. Deccan Herald. [Online]. Available: http://www.deccanherald.com/content/496911/rte-good-intent-drive-1 acking.html

[15] NITI Aayog. (2015). Programme evaluation organization, Government of India. Evaluation Study on Navodaya Vidyalaya Smiti (NVS). [Online]. Available: http://niti.gov.in/mgov_file/report-nvs.pdf

[16] M. Tones, M. Fraser, R. Elder, and K. M. White, "Supporting mature-aged students from a low socioeconomic background," Higher Educ., vol. 58, pp. 505-529, October 2009.

[17] B. I. Fozdar, L. S. Kumar, and S. Kannan, "A survey of a study on the reasons responsible for student dropout from the bachelor of science programme at Indira Gandhi National Open University," International Review of Research in Open and Distance Learning, vol. 7, no. 3, December 2006.

[18] (July 29, 2015). Government may rename Rashtriya Avishkar Abhiyaan after APJ Abdul Kalam. The Indian Express. [Online]. Available:

http://indianexpress.com/article/india/india-others/government-may-r ename-rashtriya-avishkar-abhiyan-after-apj-abdul-kalam/

[19] T. A. Campbell and D. E. Campbell, "Faculty/student mentor program: Effects on academic performance and retention," Research in Higher Education, vol. 38, no. 6, December 1997.

[20] J. L. Terrion and D. Leonard, "A taxonomy of the characteristics of student peer mentors in higher education: Findings from a literature 
review," Mentoring \& Tutoring: Partnership in Learning, vol. 15, no. 2, pp. 149-164, May 2007.

[21] S. Miles, "Make or break: The importance of good mentorship," British Journal of Midwifery, vol. 16, no. 11, September 2013.

[22] A. Bhatia, N. Singh, and U. Dhaliwal, "Mentoring for first year medical: humanising medical education," Indian Journal of Medical Ehtics, vol. 10, no. 2, April-June 2013.

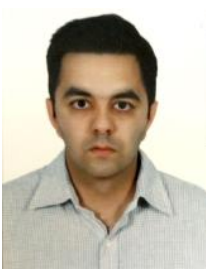

Digvijay Singh Sujlana was born in New Delhi in January 1985. He earned a bachelor of engineering from the Manipal University, India in 2007 and a post graduate diploma in management from the Indian Institute of Managemen, India in 2009. After graduating from the Indian Institute of Management in 2009 he worked in the development space with a focus on education for five years. In 2014 he joined the
National University of Singapore to pursue his interest in public policy. Mr. Sujlana is currently a recipient of the Li Ka Shing Scholarship and has also been a recipient of the DAAD scholarship. 